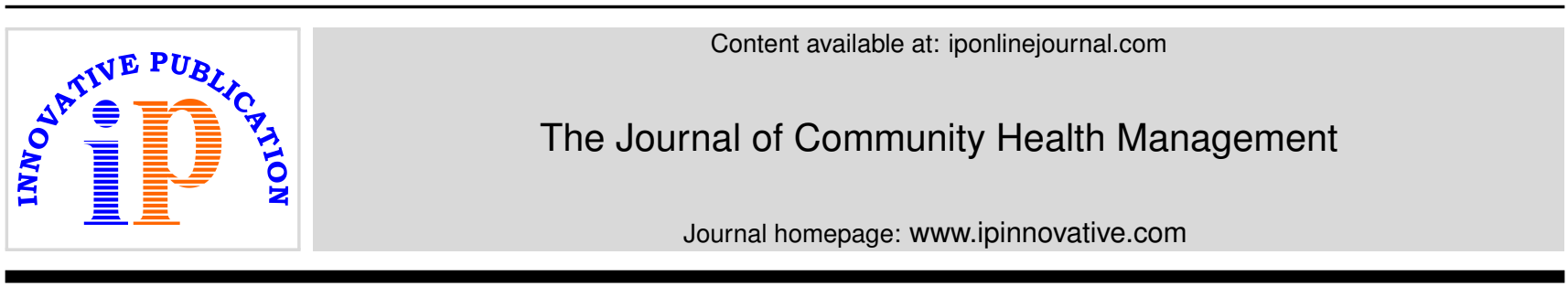

\title{
Commentary
}

\section{Chloroquine and Hydroxychloroquine: Are they really wonder drugs for COVID 19?}

\author{
MD Abu Bashar ${ }^{1, *}$, Nazia Begam ${ }^{2}$ \\ ${ }^{1}$ Dept. of Community Medicine, MM Institute of Medical Sciences \& Research, MM Deemed University, Mullana, Haryana, India \\ ${ }^{2}$ ECHS Polyclinic, Naraingarh, Haryana, India
}

\section{A R T I C L E I N F O}

Article history:

Received 04-05-2020

Accepted 11-05-2020

Available online 31-07-2020

Keywords:

Hydroxychloroquine

\begin{abstract}
A B S T R A C T
Despite limited and conflicting data on the use of Chloroquine and hydroxychloroquine in patients with Covid-19, the U.S. Food and Drug Administration(FDA) has authorized the emergency use of these drug on March 28, 2020 given the clinical trials are unavailable or infeasible. Hydroxychloroquine, alone or in combination with azithromycin, is being widely used in Covid-19 therapy based on anecdotal and limited observational evidence.
\end{abstract}

(C) 2020 Published by Innovative Publication. This is an open access article under the CC BY-NC license (https://creativecommons.org/licenses/by-nc/4.0/)

\section{Introduction}

Since the first case was reported in December 2019 from Wuhan, China, infection with the severe acute respiratory coronavirus 2 (SARS-CoV-2) i.e. COVID 19, has become a worldwide pandemic. ${ }^{1,2}$ The pandemic has also challenged the slow and highly regulated drug-approval process across the globe. ${ }^{3}$ On March 28, 2020, the U.S. Food \& Drug Authority(FDA), the highest drug approving agency across the world, authorized use of the antimalarial drugs chloroquine (CQ) and hydroxychloroquine (HCQ) to treat COVID-19 patients without any clinical trial data and despite inconclusive clinical evidence of effectiveness. ${ }^{4}$ Before that, on 22 March, 2020, National task force for COVID-19 constituted by Indian Council for Medical research (ICMR) recommended the use of hydroxylchloroquine for prophylaxis of SARS-Cov-2 infection in high risk individuals. ${ }^{5}$ The recommendation was approved by Drug controller general of India(DCGI) for restricted use in emergency situations.

Interest in these drugs was sparked by the conviction that most COVID-19 patients are probably in an antiviralsusceptible stage before clinical presentation. Following a primary phase marked by the usual respiratory symptoms,

\footnotetext{
* Corresponding author.

E-mail address: imback20006@yahoo.in (M. D. A. Bashar).
}

fevers, and malaise, patients most affected by COVID-19 develop a severe inflammatory respiratory illness, driven largely by the host immune response. Laboratory data show evidence of massive inflammation, including elevated Creactive protein, ferritin, and interleukin-6. CQ and HCQ have demonstrated activity in vitro against SARS-CoV, SARS-CoV-2, and other viruses. ${ }^{6-8}$ The mechanism is not clearly understood but it involves raising the $\mathrm{pH}$ of cellular endosomes, rendering less efficient the process of viral entry, replication, and infection and interference with glycosylation of cellular receptors for the virus. In addition, these drugs also appear to reduce host cell autophagy. ${ }^{9}$ Given these apparent antiviral and immunomodulatory effects, CQ/HCQ seemed promising. ${ }^{10}$

Emergency use Authorization of CQ/HCQ by the FDA for COVID-19 occurred primarily after the extensive publicity cause due to a small non-randomized study, of 36 patients with confirmed COVID-19; 22 having upper respiratory tract infections, 8 having lower respiratory tract infections, and 6 having no symptoms. ${ }^{11}$ Of these patients, 20 received HCQ (600 mg daily) and 16 did not (control patients). Among the HCQ patients, 6 also received azithromycin (AZM; $500 \mathrm{mg}$ on day 1,250 mg on days 2-5) as a bacterial superinfection prophylaxis. Within 6 days, virologic clearance was seen in $70 \%$ of HCQ recipients and 
in $12.5 \%$ of controls. All patients treated with $\mathrm{HCQ}+\mathrm{AZM}$ cleared virus compared with $57.1 \%$ who received HCQ alone only. ${ }^{11}$ These findings were not convincing and the effect was purely microbiological and not clinical. Further, the study was not optimally designed and was potentially subject to bias.

Notably, in previous epidemics of chikungunya, dengue, and influenza, the apparent in vitro antiviral effects of CQ/HCQ did not translate into clinical benefits. ${ }^{12}$ The first randomized study of HCQ in COVID-19 patients from China had only 30 patients from a single centre and did not show any clinical benefit. ${ }^{13}$ A second report published February 15, 2020, indicated that there were better outcomes associated with CQ therapy than in controls in a review of 100 patients, but the full results have yet to be published in a peer-reviewed journal. ${ }^{14}$

Beyond the substantial doubts about their efficacy, CQ and HCQ are not without toxicity. Photosensitivity, gastrointestinal side effects, and other toxicities - while rare - may be augmented in severely ill COVID-19 patients. Of particular concern is QT prolongation due to these agents, as myocarditis and cardiomyopathy appear to be relatively common complications in patients with severe COVID-19. ${ }^{15,16}$ Highlighting these concerns, in a doubleblind, randomized trial in Brazil of two doses of CQ $(600 \mathrm{mg}$ twice daily for 10 days or $450 \mathrm{mg}$ twice daily for 5 days) for hospitalized patients with COVID-19 recently, the higherdose arm was discontinued per data safety monitoring board for increased mortality. ${ }^{17}$ An additional retrospective review of 368 male patients hospitalized with COVID-19 in U.S. veterans medical centers, released as non-peerreviewed preprint on April 21, 2020, raised a similar concern. ${ }^{18}$ Although HCQ recipients and non-recipients differed in several baseline characteristics that could have influenced the findings, the risk for death was higher in the HCQ group than in the non-HCQ group (adjusted hazard ratio with HCQ vs. without, 2.6). ${ }^{18}$

\section{Conclusion}

Although new treatment approaches to the management of COVID-19 are required rapidly and desperately keeping in view the pandemic situation, most of the available information in relation to the use of $\mathrm{CQ} / \mathrm{HCQ}$ for COVID-19 comes from studies that were either poorly designed or available in only non-peer-reviewed preprints. Placebo-controlled studies evaluating the role of $\mathrm{CQ} / \mathrm{HCQ}$ as postexposure prophylaxis, in outpatient clinics (mild disease), and in hospitalized patients have now been started. Given the currently available limited efficacy data and the grave concerns regarding safety, we believe that $\mathrm{CQ} / \mathrm{HCQ}$ should not be used for COVID-19 until controlled clinical trials clearly demonstrate the benefits outweighing potential harms.

\section{Source of Funding}

None.

\section{Conflict of Interest}

None.

\section{References}

1. Cucinotta D, Vanelli M. WHO declares COVID-19 a pandemic. Acta Biomed. 2020;91:157-60.

2. Spinelli A, Pellino G. COVID-19 pandemic: perspectives on an unfolding crisis. Br J Surg. 2020;107(7):785-7.

3. Rome BN, Avorn J. Drug Evaluation during the Covid-19 Pandemic. N Engl J Med. 2020;382(24):2282-4.

4. Food and Drug Administration; 2020. Available from: https://WwW. Eda.gov/media//36534/download.

5. Advisory on the use of Hydroxychloroquine for SARS- COV-2 Infection. Ministry of health \& family welfare. Available from: hitps://www.mohtw.gov.1n/pdt/ AdvisoryontheuseofHydroxychloroquinasprophylaxisforSARSCoV2infection. pdt

6. Wang M, Cao R, Zhang L. Remdesivir and chloroquine effectively inhibit the recently emerged novel coronavirus $(2019-\mathrm{nCoV})$ in vitro. Cell Res. 2020;30:269-71.

7. Biot C, Daher W, Chavain N, Fandeur T, Khalife J, Dive D, et al. Design and Synthesis of Hydroxyferroquine Derivatives with Antimalarial and Antiviral Activities. J Med Chem. 2006;49(9):28459.

8. Liu J, Cao R, Xu M. Hydroxychloroquine, a less toxic derivative of chloroquine, is effective in inhibiting SARS-CoV-2 infection in vitro. Cell Discov. 2020;6:16-16.

9. Yan Y, Zou Z, Sun Y. Anti-malaria drug chloroquine is highly effective in treating avian influenza A H5N1 virus infection in an animal model. Cell Res. 2013;23(2):300-2.

10. Colson P, Rolain JM, Raoult D. Chloroquine for the 2019 novel coronavirus SARS-CoV-2. Int $J$ Antimicrob Agents. 2020;55(3): 105923.

11. Gautret P, Lagier JC, Parola P. Hydroxychloroquine and azithromycin as a treatment of COVID-19: results of an open-label non-randomized clinical trial. Int J Antimicrob Agents. 2020;p. 105949.

12. Paton NI, Lee L, Xu Y. Chloroquine for influenza prevention: a randomised, double-blind, placebo controlled trial. Lancet Infect Dis. 2011;11:677-83.

13. Chen J, Liu D, Liu L. A pilot study of hydroxychloroquine in treatment of patients with common coronavirus disease-19 (COVID-19). J Zhejiang Univ (Med Sci). 2020;49(1).

14. Gao J, Tian Z, Yang X. Breakthrough: Chloroquine phosphate has shown apparent efficacy in treatment of COVID-19 associated pneumonia in clinical studies. Biosci Trends. 2020;14(1):72-3.

15. Sanders JM, Monogue ML, Jodlowski TZ, Cutrell JB. Pharmacologic Treatments for Coronavirus Disease 2019 (COVID-19). JAMA. 2020 doi:10.1001/jama.2020.6019

16. Chorin E, Dai M, Shulman E. The QT interval in patients with COVID-19 treated with hydroxychloroquine and azithromycin. Nat Med. 2020;

17. Chloroquine diphosphate in two different dosages as adjunctive therapy of hospitalized patients with severe respiratory syndrome in the context of coronavirus (SARS-CoV-2) infection: Preliminary safety results of a randomized, double-blinded, phase IIb clinical trial (CloroCovid-19 Study). medRxiv.

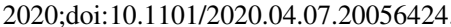

18. Magagnoli J, Narendran S, Pereira F, Cummings TH, Hardin JW, Sutton SS, et al. Outcomes of hydroxychloroquine usage in United States veterans hospitalized with Covid-19. Med (N Y). 2020;01:10.1016/j.medj.2020.06.00] 


\section{Author biography}

MD Abu Bashar Assistant Professor
Cite this article: Bashar MDA, Begam N. Chloroquine and

Hydroxychloroquine: Are they really wonder drugs for COVID 19?. J

Community Health Manag 2020;7(2):64-66.

Nazia Begam Specialist M.O 